\title{
Fluorosilane Water-Repellent Coating for the Protection of Marble, Wood and Other Materials
}

\author{
Fotios G. Adamopoulos ${ }^{1,2}$, Evangelia C. Vouvoudi ${ }^{1}$, Dimitris S. Achilias ${ }^{1}$ (D) and Ioannis Karapanagiotis ${ }^{2, *(\mathbb{D})}$ \\ 1 Laboratory of Polymers and Dyes Chemistry and Technology, Department of Chemistry, Aristotle University \\ of Thessaloniki, GR-54124 Macedonia, Greece; r2r5r1r5r7@yahoo.gr (F.G.A.); \\ evouvoud@chem.auth.gr (E.C.V.); axilias@chem.auth.gr (D.S.A.) \\ 2 Department of Management and Conservation of Ecclesiastical Cultural Heritage Objects, \\ University Ecclesiastical Academy of Thessaloniki, GR-54250 Thessaloniki, Greece \\ * Correspondence: y.karapanagiotis@aeath.gr
}

Citation: Adamopoulos, F.G.; Vouvoudi, E.C.; Achilias, D.S.; Karapanagiotis, I. Fluorosilane Water-Repellent Coating for the Protection of Marble, Wood and Other Materials. Heritage 2021, 4 , 2668-2675. https://doi.org/ $10.3390 /$ heritage 4040150

Academic Editors:

Antonia Moropoulou,

Elisabetta Zendri, Ekaterini Delegou and Michael Turner

Received: 31 August 2021

Accepted: 23 September 2021

Published: 25 September 2021

Publisher's Note: MDPI stays neutral with regard to jurisdictional claims in published maps and institutional affiliations.

Copyright: (c) 2021 by the authors. Licensee MDPI, Basel, Switzerland. This article is an open access article distributed under the terms and conditions of the Creative Commons Attribution (CC BY) license (https:/ / creativecommons.org/licenses/by/ $4.0 /)$.

\begin{abstract}
The preservation of cultural heritage monuments and artifacts requires the development of methods to produce water-repellent materials, which can offer protection against the effects of atmospheric water. Fluorosilanes are a very promising class of materials, as they act as precursors for the formation of low surface energy polymer networks. $1 \mathrm{H}, 1 \mathrm{H}, 2 \mathrm{H}, 2 \mathrm{H}$-perfluorooctyl-triethoxysilane is applied on marble, wood and the surfaces of other materials, such as glass, silicon wafer, brass, paper and silk. According to the measurements of static water contact angles, it is reported that superhydrophobicity and enhanced hydrophobicity are achieved on the surfaces of coated marble and wood, respectively. Hydrophobicity and hydrophilicity were observed on the treated surfaces of the other materials. More important, water repellency is achieved on any hydrophobic or superhydrophobic surface, as revealed by the very low sliding angles of water drops. The study is accompanied by colorimetric measurements to evaluate the effects of the treatment on the aesthetic appearances of the investigated materials. Finally, the capillary absorption test and a durability test are applied on treated wood and marble, respectively.
\end{abstract}

Keywords: hydrophobic; superhydrophobic; water repellent; fluorosilane; contact angle

\section{Introduction}

The preservation of the cultural identity may be accomplished by the promotion of the remaining monuments, buildings and artifacts of the cultural heritage. Modern conceptions of conservation strategies are seen as integrated economic development approaches, similar to parallel processes of improving infrastructure and promoting cultural projects [1]. Thus, it turns out that the preservation, restoration, documentation and promotion of the cultural heritage is a sustainability obligation. Conservation products, which have been developed to protect cultural heritage objects and buildings against environmental pollution, human interventions or natural deterioration, should fulfill specific requirements. The activities and applications of these materials depend heavily on their chemical composition and structure.

Alkoxysilanes, for instance, are widely used for the protection and consolidation of buildings, mainly due to their low viscosity, which allows them to penetrate deep into the interior of the natural stone [2]. Upon application, the small silane and siloxane molecules are polymerized in situ through a sol-gel process, forming a polysiloxane network that improves the mechanical stability and durability of the treated stone [2,3]. Moreover, the application of carefully designed sol-gel processes can result in the production of superhydrophobic and water-repellent polysiloxane materials [4,5], which apparently offer enhanced protection against the degradation effects of atmospheric water. Superhydrophobicity is defined by the very large static water contact angle (typically $>150^{\circ}$ ), whereas a water-repellent surface is characterized by the low sliding angle of water drop (typically $<10^{\circ}$ ). Nanocomposites, 
which consist of nanoparticles embedded in polysiloxane networks, are a new class of advanced materials, designed for the protection of stone [6-16]. Extreme hydrophobicity or even superhydrophobicity is achieved on the surfaces of these nanocomposites, as the additives-nanoparticles promote surface roughness [6-16]. According to the Cassie-Baxter model, which is commonly used to describe non-wetting phenomena, the hydrophobic character of any material is enhanced with surface roughness [17].

The replacement of hydrogen $(\mathrm{H})$ atoms with fluorine $(\mathrm{F})$ atoms in a polymeric structure enhances its ability to endure heat, light, flame, moisture or chemicals [18]. Moreover, $\mathrm{F}$ atoms reduce the surface energy of the material and hence increase hydrophobicity. For these reasons, fluorinated polymers have been extensively investigated and suggested for the conservation of buildings and objects of the cultural heritage that are exposed to atmospheric conditions [19-25].

The static and the sliding angles of a water drop on a surface are used to assess the hydrophobic/hydrophilic and water-repellent/adhesive character of the surface, respectively. It is stressed that hydrophobicity is not always accompanied by water repellency. For example, the surface of rose petal shows superhydrophobicity (i.e., the static water contact angle is $>150^{\circ}$ ), and yet the water drop remains pinned on this natural surface even if it is turned upside down, implying high drop adhesion (i.e., the sliding angle cannot be practically measured) [26,27]. Therefore, both static and sliding angles are important to characterize the wettability of a surface. It turns out that for practical applications such as the protection of buildings that are exposed to outdoor conditions, water repellency (i.e., a small sliding angle of water drop) is the key, desirable property. Only on a waterrepellent surface does the water drop roll off the surface easily, collecting dirt along the way (self-cleaning scenario) [28].

As described above, contact angle measurements are extremely important in order to study the interaction of water with a material designed for the protection of cultural heritage. Moreover, the evaluation of the color parameters after the application of protective coatings onto materials of cultural heritage is essential, since the alteration of the original hue is forbidden.

The goal of the present study is to investigate the efficacy of $1 \mathrm{H}, 1 \mathrm{H}, 2 \mathrm{H}, 2 \mathrm{H}$-perfluorooctyltriethoxysilane (FAS) to induce hydrophobicity, and more importantly water repellency, on various cultural heritage materials such as marble, wood, glass, brass, paper and silk. More experiments are carried out on marble and wood (capillary absorption test and a durability test), which are commonly found in buildings and objects exposed to atmospheric water. Moreover, a silicon ( $\mathrm{Si}$ ) wafer is included in the investigation, as this is a smooth surface that is commonly used in wettability studies. Finally, colorimetric measurements are carried out.

\section{Materials and Methods}

\subsection{Materials Preparation}

FAS silane solution was prepared by $1 \mathrm{H}, 1 \mathrm{H}, 2 \mathrm{H}, 2 \mathrm{H}$-perfluorooctyl-triethoxysilane (97\%) $\left(\mathrm{C}_{14} \mathrm{H}_{19} \mathrm{~F}_{13} \mathrm{O}_{3} \mathrm{Si}\right.$ ) (CAS\# 51851-37-7, Sigma Aldrich, St. Louis, MO, USA). One gram of FAS was mixed with $99 \mathrm{~g}$ of ethanol (ChemLab, $>98 \%$ ) and stirred for $2 \mathrm{~h}$ while $\mathrm{pH}$ was over 8 . Most materials that were treated with the FAS solution were obtained from the local market: blocks of white (Thassos) marble and beech wood, glass slides, filter paper (Whatman No 4), polished brass specimens and silk. As for silicon (Si) wafers, these were obtained from Siegert Wafer (Aachen, Germany). Except for silk and paper, substrate materials were washed with tap water then rinsed with deionized water and acetone. They remained in ambient conditions for 4 days in order to dry, while for total moisture removal, the specimens were placed in a Thermconcept oven (KL 15/12) for $48 \mathrm{~h}$ at $80^{\circ} \mathrm{C}$. Blocks of marble and wood with dimensions of $5 \mathrm{~cm} \times 5 \mathrm{~cm} \times 2 \mathrm{~cm}$ and $2 \mathrm{~cm} \times 2 \mathrm{~cm} \times 2 \mathrm{~cm}$, respectively, were used.

The colorless sol was deposited onto marble, glass, Si wafer, brass, paper and silk using a Da Vinci Forte Basic No 4 brush. Six brush strokes were applied, with each covering 
being applied to the opposite direction of the previous one after the previous one had dried. Wood specimens were treated with the dip-coating method: samples were partially immersed by $1 \mathrm{~cm}$ in the sol for $50 \mathrm{~h}$. After coating deposition, samples were left to dry. Coated and uncoated samples were weighted to measure the coating uptake.

\subsection{Instrumentation and Characterization Tests}

Static contact and sliding angles were measured using an optical tensiometer apparatus (Attension Theta, Gothenburg, Sweden). Three drops of distilled water were placed at three different spots on coated substrates. For the measurements of the sliding angles, the tilt rate was adjusted to $1 \%$ s. Colorimetric measurements were carried out using a MiniScan XE Plus spectrophotometer (HunterLab, Reston, VA, USA), and the results were evaluated using the $\mathrm{L}^{*}, \mathrm{a}^{*}, \mathrm{~b}^{*}$ coordinates of the CIE 1976 scale [29]. The reported results are averages of three measurements. The silane uptake was measured gravimetrically (Sartorius, Göttingen, Germany).

Compared to other materials, more tests were carried out on wood and marble, which are of particular interest. For water absorption by the capillary effect, the pre-weighted wood specimen was placed with the coated side downwards into a vessel with distilled water for $2 \mathrm{~h}$ at ambient conditions. The weight was then recorded every $5 \mathrm{~min}$, after removing softly the extra moisture from the coated surface. The calculation was carried out via the fraction below (1), where $\mathrm{w}_{\mathrm{i}}(\mathrm{g})$ is the specimen mass at each $\mathrm{t}_{\mathrm{i}}$ time interval, $w_{0}$ $(\mathrm{g})$ is the initial mass, and $\mathrm{A}\left(\mathrm{cm}^{2}\right)$ is the area of the dipped surface.

$$
Q_{i}=\frac{w_{i}-w_{0}}{A}
$$

The durability of the FAS coating on marble was evaluated following a test that combined mechanical and chemical treatment, as follows: the coated marble surface was gently scratched for $30 \mathrm{~s}$ with a brush that had been immersed in acetone. The static contact angle was measured on the treated marble surface after the cleaning process, which was repeated until the surface obtained hydrophilic properties.

\section{Results and Discussion}

According to the results in Table 1, the substrate material that retained the greatest amount of coating per unit area was that of wood, which was treated with the dip-coating method. Approximately the same amount of coating was deposited onto the $\mathrm{Si}$ wafer which was treated by brush. A smaller amount of the silane material was fixed on marble, compared to wood. Considering that the size of the pores and the active porosity are lower for marble than for wood, we can conclude that more silane quantity was settled on the marble surface compared to wood surface. Next, with respect to coating uptake, was brass followed by glass. Paper and silk retained low amounts of silane material. Both paper and silk are highly hygroscopic materials, and their specimens used in the study were very thin. Thicknesses were $0.7 \mathrm{~mm}$ for the paper and $0.8 \mathrm{~mm}$ for the silk samples, respectively. Because of their small thicknesses, the two organic materials retained only small amounts of the deposited silane.

Table 1. Quantities of silane deposited on substrate materials.

\begin{tabular}{|c|c|c|}
\hline Substrate & Coating Method & $\begin{array}{c}\text { Uptake } \\
\text { (g Coating } / \mathrm{cm}^{2} \text { Substrate) }\end{array}$ \\
\hline Marble & Brush & $0.0045 \pm 0.0010$ \\
\hline Wood & Dip coating & $0.0572 \pm 0.0050$ \\
\hline Glass & Brush & $0.0375 \pm 0.0010$ \\
\hline Si wafer & Brush & $0.0500 \pm 0.0020$ \\
\hline Brass & Brush & $0.0042 \pm 0.0020$ \\
\hline Paper & Brush & $0.0011 \pm 0.0002$ \\
\hline Silk & Brush & $0.0002 \pm 0.0001$ \\
\hline
\end{tabular}


The static water contact angles, which were measured on coated substrate materials, are provided in Table 2 and show a large variation, ranging from superhydrophobicity to hydrophilicity. In particular, superhydrophobicity (static contact angle $>150^{\circ}$ ) was achieved on the surface of coated marble. Enhanced hydrophobicity was reported on the surface of coated wood, as evidenced by the large static contact angle $\left(=133.6^{\circ}\right)$. The surface structure of a deposited polymer coating is affected by the roughness of the underlying substrate [8]. As both marble and wood are rough materials, it should be expected that the resulting surfaces of the deposited FAS coatings will exhibit enhanced roughnesses. As described in the Introduction, the Cassie-Baxter model predicts that roughness promotes the hydrophobic character of a material. Hence, the origin of the large static contact angles achieved on treated marble and wood should be the high roughnesses of the two substrate materials. As concluded from the results of Table 1, more silane quantity was settled on the marble surface compared to the wood surface. Consequently, a better coverage was obtained on the marble surface, compared to wood, and therefore a higher contact angle was achieved on the coated inorganic material (Table 2). The surfaces of glass and Si wafer are smooth, corresponding to comparable roughnesses. Therefore, the structures of the coatings that were deposited on these two substrate materials should be approximately similar. This argument is supported by the measured contact angles on coated glass and Si wafer, which were within only $114.8^{\circ}-110.7^{\circ}$. As shown in Table 1 , brass retained a very small quantity of the deposited coating, thus resulting in a very low static contact angle $\left(=99.1^{\circ}\right)$, which, however, is within the hydrophobic regime. Finally, according to the results in Table 2, the deposition of the FAS material on paper and silk did not have any major effect on their wettabilities. The surfaces of coated paper and silk remained in the hydrophilic regime, probably because these two substrate materials were able to retain very small coating quantities (Table 1 ).

Table 2. Static contact angles and sliding angles of water drops on coated substrates.

\begin{tabular}{cccc}
\hline Substrate & Coating Method & Contact Angle $\left({ }^{\circ}\right)$ & Sliding Angle $\left({ }^{\circ}\right)$ \\
\hline Marble & Brush & $155.0 \pm 2.4$ & $2.7 \pm 0.2$ \\
Wood & Dip coating & $133.6 \pm 1.3$ & $1.6 \pm 0.2$ \\
Glass & Brush & $114.8 \pm 2.1$ & $1.9 \pm 0.2$ \\
Si wafer & Brush & $110.7 \pm 2.6$ & $2.3 \pm 0.1$ \\
Brass & Brush & $99.1 \pm 1.1$ & $5.3 \pm 0.1$ \\
Paper & Brush & $<90^{\circ}$ & \\
Silk & Brush & $<90^{\circ}$ & \\
\hline
\end{tabular}

Furthermore, the results of Table 2 show that the surfaces with a static water contact angle $>90^{\circ}$ exhibited augmented water repellency, as evidenced by the low sliding angles of water drops. Moreover, focusing on the superhydrophobic surface of marble and the hydrophobic surfaces of wood, glass, $\mathrm{Si}$ wafer and brass, it is seen that there is no correlation between the static contact angles, which show a large variation, and the sliding angles, which varied within a very short range, from $1.6^{\circ}$ to $5.3^{\circ}$. This result is in agreement with previously published reports, which suggested that the static contact angle is not correlated with the adhesive or repulsive performance of a surface [26,27,30-32]. The latter is described by the sliding angle or contact angle hysteresis [30-32]. Furthermore, it was demonstrated that fluorosilanes are water-repellent materials, thus corresponding to low sliding angles [33,34]. The water-repellent character of the fluorosilane used in the present study is clearly evidenced by the very low sliding angles reported in Table 2.

Photographs of water drops on coated marble, wood, glass, brass and Si wafer are shown in Figure 1. The photographs reveal the hydrophobic characters of the surfaces of the aforementioned materials. Superhydrophobicity and enhanced hydrophobicity are evidenced on coated marble and wood, respectively. 

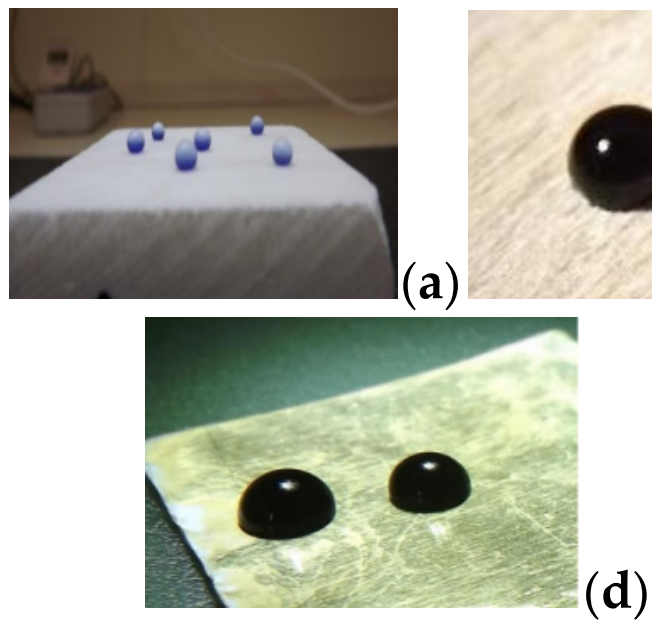

(b)
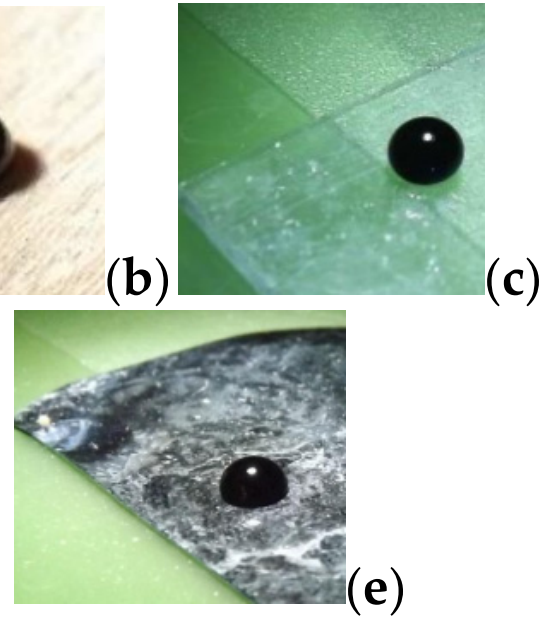

c)

Figure 1. Photographs of colored water drops on coated substrates: marble (a), wood (b), glass (c), brass (d) and Si wafer (e).

The interaction of liquid water with coated wood was further investigated by performing the capillary water absorption test. For comparison, uncoated wood specimen was included in the study. The results are provided in Figure 2, which shows the amounts of water per unit area $\left(\mathrm{Q}_{\mathrm{i}}\right)$ absorbed by the two wood specimens after being in contact with water for time $t_{i}$. Despite the water-repellent character of the coated wood surface (Table 2), the results of Figure 2 suggest that the FAS coating offered practically no protection against the capillary rise of water. This result elucidates the weak durability of the FAS coating when it is in contact with liquid water for prolonged time.

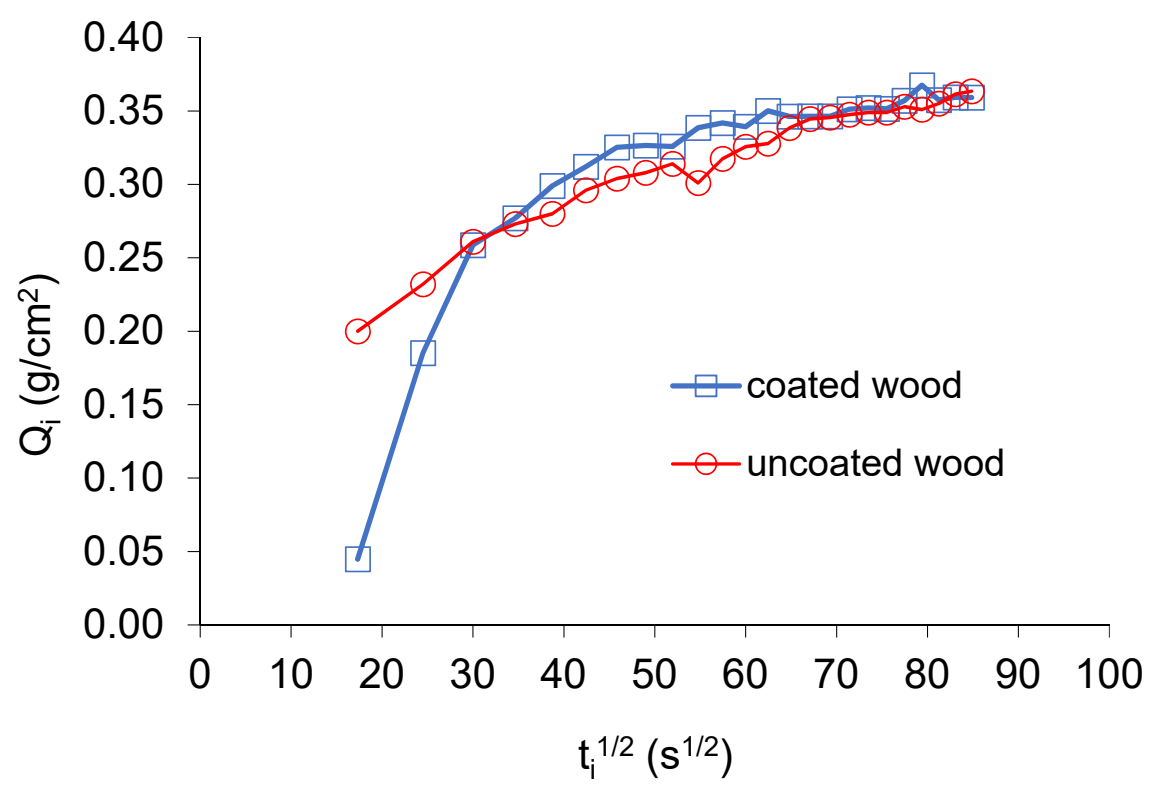

Figure 2. Results of the water capillary absorption test on coated and uncoated wood samples. The plot shows the amount of absorbed water per unit area $\left(Q_{i}\right)$ as a function of the square root of treatment time $t_{i}$.

The results of colorimetry measurements are presented in Table 3 . It can be seen that the FAS coating caused a minimal color change on the marble specimen $\left(\Delta \mathrm{E}^{*}<1\right)$. The color change of wood $\left(\Delta \mathrm{E}^{*}=3.2\right)$ induced by the application of the coating was nearly invisible, as it just exceeded the limit $\left(\Delta \mathrm{E}^{*}=3\right)$ above which the human eye can perceive a color change. Similarly, the color of the paper specimen did not change after its processing $\left(\Delta \mathrm{E}^{*}=0.46\right)$. A noticeable color change $\left(\Delta E^{*}=5.3\right)$ is reported in Table 3 for glass, originating primarily 
by the large change of brightness $\left(\Delta \mathrm{L}^{*}\right)$. The high values of the latter $\left(\Delta \mathrm{L}^{*}\right)$ contributed to the significant color changes observed on the surfaces of Si wafer $\left(\Delta \mathrm{E}^{*}=19.77\right)$, brass $\left(\Delta \mathrm{E}^{*}=14.9\right)$ and silk $\left(\Delta \mathrm{E}^{*}=13.2\right)$. However, major contributions to the calculated $\Delta \mathrm{E}^{*}$ for $\mathrm{Si}$ wafer and brass were provided by the large changes of the yellow-blue component $\left(\Delta \mathrm{b}^{*}\right)$.

Table 3. Color measurements.

\begin{tabular}{cccccc}
\hline Substrate & Coating Method & $\boldsymbol{\Delta} \mathbf{L}^{*}$ & $\boldsymbol{\Delta} \mathbf{a}^{*}$ & $\boldsymbol{\Delta} \mathbf{b}^{*}$ & $\boldsymbol{\Delta} \mathbf{E}^{*}$ \\
\hline Marble & Brush & 0.07 & 0.22 & 0.26 & $0.30 \pm 0.05$ \\
Wood & Dip coating & 3.04 & 0.55 & 0.64 & $3.20 \pm 1.47$ \\
Glass & Brush & 5.02 & 0.81 & 1.59 & $5.30 \pm 0.10$ \\
Si wafer & Brush & 19.37 & 0.09 & 4.00 & $19.77 \pm 0.50$ \\
Brass & Brush & 8.75 & 0.17 & 12.06 & $14.90 \pm 0.60$ \\
Paper & Brush & 0.46 & 0.05 & 0.05 & $0.46 \pm 0.10$ \\
Silk & Brush & 13.14 & 0.72 & -1.09 & $13.20 \pm 0.30$ \\
\hline
\end{tabular}

In order to test the durability of the treatment, the coated marble surface was brushed for $30 \mathrm{~s}$. Before using it, the brush had been immersed in acetone. According to the results of Table 2 , the static contact angle on coated marble was around $155.0^{\circ}$. After the application of the cleaning process (first cycle), the contact angle was reduced to $147.3^{\circ}$. The cleaning process was repeated three more times. After the second, third and fourth cleaning cycles, the contact angle on treated marble became $126.6^{\circ}, 103.5^{\circ}$ and $89.46^{\circ}$, respectively. Therefore, it took four cycles to record a transition from superhydrophobicity to hydrophilicity.

\section{Conclusions}

$1 \mathrm{H}, 1 \mathrm{H}, 2 \mathrm{H}, 2 \mathrm{H}$-perfluorooctyl-triethoxysilane was applied on marble, wood, glass, silicon wafer, brass, paper and silk samples. Static water contact angles ranging from $155^{\circ}$ (for coated marble) to values lower than $90^{\circ}$ (for coated paper and silk) were measured on the different treated materials. Low sliding angles of water drops $\left(<6^{\circ}\right)$ were measured on coated materials, except for the hydrophilic paper and silk. Consequently, it is reported that water repellency was achieved on coated marble, wood, glass, silicon wafer and brass. The application of the FAS coating induced negligible and considerable color changes to marble and paper $\left(\Delta \mathrm{E}^{*}<0.5\right)$ and to wood and glass $\left(3.0<\Delta \mathrm{E}^{*}<5.5\right)$, respectively. The treatment had a major effect on the aesthetic appearances of silicon wafer, brass and silk $\left(\Delta E^{*}>13\right)$. The capillary rise test was carried out on coated wood and showed that the FAS coating offered practically no protection against the absorption of water. Finally, a quick, preliminary test showed that the FAS coating on marble exhibits good durability. However, the durability and the behavior of the FAS coating after accelerated aging conditions or prolonged natural aging should be tested in the future.

Author Contributions: Conceptualization, F.G.A. and I.K.; Methodology, F.G.A. and I.K.; Investigation, F.G.A.; Data Curation, F.G.A. and E.C.V.; Writing-Original Draft Preparation, E.C.V.; Writing-Review \& Editing, E.C.V. and I.K.; Supervision, I.K. and D.S.A.; Project Administration, D.S.A. All authors have read and agreed to the published version of the manuscript.

Funding: This research received no external funding.

Institutional Review Board Statement: Not applicable.

Informed Consent Statement: Not applicable.

Data Availability Statement: Data available on request from the authors.

Acknowledgments: The authors would like to thank E. Pavlidou and C. Papoulia (Aristotle University of Thessaloniki) for useful discussions.

Conflicts of Interest: The authors declare no conflict of interest. 


\section{References}

1. Lukaszewicz, J.W.; Lukaszewicz, J.P. Historic Heritage Protection as Part of Sustainable Growth. In Gulf Conference on Sustainable Built Environment; Springer International Publishing: Basel, Switzerland, 2020.

2. Wheeler, G. Alkoxysilanes and the Consolidation of Stone; Getty Publications: Los Angeles, CA, USA, 2005.

3. Delgado Rodrigues, J. Consolidation of decayed stones. A delicate problem with few practical solutions. In Historical Constructions; Lourenço, P.B., Roca, P., Eds.; University of Minho: Guimarães, Portugal, 2001.

4. Karapanagiotis, I.; Pavlou, A.; Manoudis, P.N.; Aifantis, K.E. Water repellent ORMOSIL films for the protection of stone and other materials. Mater. Lett. 2014, 131, 276-279. [CrossRef]

5. Adamopoulos, F.G.; Vouvoudi, E.C.; Pavlidou, E.; Achilias, D.S.; Karapanagiotis, I. TEOS-based superhydrophobic coating for the protection of stone-built cultural heritage. Coatings 2021, 11, 135. [CrossRef]

6. Manoudis, P.; Papadopoulou, S.; Karapanagiotis, I.; Tsakalof, A.; Zuburtikudis, I.; Panayiotou, C. Polymer-Silica nanoparticles composite films as protective coatings for stone-based monuments. J. Phys. Conf. Ser. 2007, 61, 1361-1365. [CrossRef]

7. Manoudis, P.; Tsakalof, A.; Karapanagiotis, I.; Zuburtikudis, I.; Panayiotou, C. Fabrication of super-hydrophobic surfaces for enhanced stone protection. Surf. Coat. Technol. 2009, 203, 1322-1328. [CrossRef]

8. Manoudis, P.N.; Karapanagiotis, I.; Tsakalof, A.; Zuburtikudis, I.; Kolinkeová, B.; Panayiotou, C. Superhydrophobic films for the protection of outdoor cultural heritage assets. Appl. Phys. A 2009, 97, 351-360. [CrossRef]

9. Chatzigrigoriou, A.; Manoudis, P.N.; Karapanagiotis, I. Fabrication of water repellent coatings using waterborne resins for the protection of the cultural heritage. Macromol. Symp. 2013, 331-332, 158-165. [CrossRef]

10. Cappelletti, G.; Fermo, P.; Camiloni, M. Smart hybrid coatings for natural stones conservation. Prog. Org. Coat. 2015, 78, 511-516. [CrossRef]

11. Facio, D.S.; Carrascosa, L.A.M.; Mosquera, M.J. Producing lasting amphiphobic building surfaces with self-cleaning properties. Nanotechnology 2017, 28, 265601. [CrossRef]

12. Helmi, F.M.; Hefni, Y.K. Using nanocomposites in the consolidation and protection of sandstone. Int. J. Conserv. Sci. 2016, 7, 29.

13. Pino, F.; Fermo, P.; La Russa, M.; Ruffolo, S.; Comite, V.; Baghdachi, J.; Pecchioni, E.; Fratini, F.; Cappelletti, G. Advanced mortar coatings for cultural heritage protection. Durability towards prolonged UV and outdoor exposure. Environ. Sci. Pollut. Res. 2017, 24, 12608-12617. [CrossRef]

14. Zarzuela, R.; Carbú, M.; Gil, M.L.A.; Cantoral, J.M.; Mosquera, M.J. Ormosils loaded with $\mathrm{SiO}_{2}$ nanoparticles functionalized with Ag as multifunctional superhydrophobic/biocidal/consolidant treatments for buildings conservation. Nanotechnology 2019, 30, 345701. [CrossRef]

15. Chatzigrigoriou, A.; Karapanagiotis, I.; Poulios, I. Superhydrophobic coatings based on siloxane resin and calcium hydroxide nanoparticles for marble protection. Coatings 2020, 10, 334. [CrossRef]

16. Karapanagiotis, I.; Manoudis, P. Superhydrophobic and water repellent polymer-nanoparticle composite films. In Industrial Applications for Intelligent Polymers and Coatings; Hosseini, M., Makhlouf, A.S.H., Eds.; Springer International Publishing: Basel, Switzerland, 2016; pp. 205-221.

17. Cassie, A.B.D.; Baxter, S. Wettability of porous surfaces. Trans. Faraday Soc. 1944, 40, 546-551. [CrossRef]

18. Yao, W.; Li, Y.; Huang, X. Fluorinated poly(meth)acrylate: Synthesis and properties. Polymers 2014, 55, 6197-6211. [CrossRef]

19. Aslanidou, D.; Karapanagiotis, I.; Panayiotou, C. Tuning the wetting properties of siloxane-nanoparticle coatings to induce superhydrophobicity and superoleophobicity for stone protection. Mater. Des. 2016, 108, 736-744. [CrossRef]

20. Aslanidou, D.; Karapanagiotis, I.; Lampakis, D. Waterborne superhydrophobic and superoleophobic coatings for the protection of marble and sandstone. Materials 2018, 11, 585. [CrossRef]

21. Mosquera, M.J.; Carrascosa, L.A.M.; Badreldin, N. Producing superhydrophobic/oleophobic coatings on Cultural Heritage building materials. Pure Appl. Chem. 2018, 90, 551-561. [CrossRef]

22. Colangiuli, D.; Calia, A.; Bianco, N. Novel multifunctional coatings with photocatalytic and hydrophobic properties for the preservation of the stone building heritage (review). Constr. Build. Mater. 2015, 93, 189. [CrossRef]

23. Alessandrini, G.; Aglietto, M.; Castelvetro, V.; Ciardelli, F.; Peruzzi, R.; Toniolo, L. Comparative evaluation of fluorinated and unfluorinated acrylic copolymers as water-repellent coating materials for stone. J. Appl. Polym. Sci. 2000, 76, 962-977. [CrossRef]

24. Tian, S.; Liu, S.; Gao, F.; Fan, M.; Ren, J. Preparation and assessment of superhydrophobic organic-inorganic hybrid coatings for conservation of Yungang grottoes. MRS Proc. 2011, 1319, 333. [CrossRef]

25. La Russa, M.F.; Rovella, N.; De Buergo, M.A.; Belfiore, C.M.; Pezzino, A.; Crisci, G.M.; Ruffolo, S.A. Nano-TiO 2 coatings for cultural heritage protection: The role of the binder on hydrophobic and self cleaning efficacy. Prog. Org. Coat. 2016, 91, 1. [CrossRef]

26. Feng, L.; Zhang, Y.; Xi, J.; Zhu, Y.; Wang, N.; Xia, A.F.; Jiang, L. Petal Effect: A superhydrophobic state with high adhesive force. Langmuir 2008, 24, 4114-4119. [CrossRef]

27. Manoudis, P.N.; Gemenetzis, D.; Karapanagiotis, I. A comparative study of the wetting properties of a superhydrophobic siloxane material and rose petal. Sci. Cult. 2017, 3, 7.

28. Fürstner, R.; Barthlott, W.; Neinhuis, C.; Walzel, P. Wetting and self-cleaning properties of artificial superhydrophobic surfaces. Langmuir 2005, 21, 956-961. [CrossRef] [PubMed]

29. CEN. EN15886, Conservation of Cultural Property-Test Methods-Colour Measurement of Surfaces; CEN: Brussels, Belgium, 2010. 
30. Murase, H.; Fujibayashi, T. Characterization of molecular interfaces in hydrophobic systems. Prog. Org. Coat. 1997, 31, 97-104. [CrossRef]

31. Rios, P.F.; Dodiuk, H.; Kenig, S.; McCarthy, S.; Dotan, A. The effect of polymer surface on the wetting and adhesion of liquid systems. J. Adhes. Sci. Technol. 2007, 21, 227-241. [CrossRef]

32. Samuel, B.; Zhao, H.; Law, K.-Y. Study of wetting and adhesion interactions between water and various polymer and superhydrophobic surfaces. J. Phys. Chem. C 2011, 115, 14852-14861. [CrossRef]

33. Pellerite, M.J.; Wood, E.J.; Jones, V.W. Dynamic contact angle studies of self-assembled thin films from fluorinated alkyltrichlorosilanes. J. Phys. Chem. B 2002, 106, 4746. [CrossRef]

34. Muschi, M.; Brudieu, B.; Teisseire, J.; Sauret, A. Drop impact dynamics on slippery liquid-infused porous surfaces: Influence of oil thickness. Soft Matter 2018, 14, 1100-1107. [CrossRef] [PubMed] 